\title{
A pedologia como polígrafo da pedagogia (pressupostos psicopedagógicos) em Faria de Vasconcelos (1880-1939)
}

Paedology as a polygraph of pedagogy (psychopedagogical assumptions) in Faria de Vasconcelos (1880-1939)

Pedología como polígrafo de la Pedagogía (suposiciones psicopedagógicas) en Faria de Vasconcelos (1880-1939)

\author{
Ernesto Candeias Martins \\ Instituto Politecnico de Castelo Branco (Portugal) \\ https://orcid.org/0000-0003-4841-1215 \\ ernesto@ipcb.pt
}

\begin{abstract}
Resumo
O estudo, de índole histórico-descritivo na área da História da Educação, aborda os pressupostos psicopedagógicos da Pedologia, como ciência do desenvolvimento da criança fundada na Pedagogia, propostos pelo pedagogo português Faria de Vasconcelos. Analisaremos e refletiremos, na base duma metodologia hermenêutica, o conteúdo desses aspetos na sua obra e recorrendo a fontes secundárias sobre esta temática. Este pedagogo impregnado de ideias do Movimento da Escola Nova, associadas à sua experiência em Bierges (Bélgica) fornece contributos ao estudo científico da criança/infância. Os dois pontos da estrutura do texto coincidem com os objetivos estabelecidos: analisar a Pedagogia norteada pela Pedologia, no estudo do desenvolvimento da criança, sustentando-se na pedagogia experimental; interpretar os pressupostos psicopedagógicos do crescimento e autonomia da criança, as funções físicopsíquicas (princípios: continuidade e solidariedade) e o humanismo antropológico. Vasconcelos é um dos promotores da Pedotecnia e da psicopedagogia no estudo das crianças escolares na História da Educação em Portugal.
\end{abstract}

Palavras-chave: Faria de Vasconcelos. Pedologia/Paidologia. Ideias da Escola Nova. 


\begin{abstract}
The study, of a historical-descriptive nature in the area of the History of Education, addresses the psychopedagogical assumptions of 'Pedology', as a child development science founded in Pedagogy, proposed by the pedagogue Portuguese Faria de Vasconcelos. We will analyze and reflect, on the basis of a hermeneutic methodology, the content of these aspects in his work and using secondary sources on this subject. This pedagogue impregnated with ideas from the New School Movement, associated with his experience in Bierges (Belgium) provides contributions to the scientific study of children/childhood. The two points of the structure of the text coincide with the established objectives: to analyze the Pedagogy based on Pedology, in the study of the child's development, based on experimental pedagogy; to interpret the psychopedagogical assumptions of the child's growth and autonomy, the physical-psychic functions (principles: continuity and solidarity) and anthropological humanism. Vasconcelos is one of the promoters of Paidotécnia and psychopedagogy in the study of school children in the History of Education in Portugal.
\end{abstract}

Keywords: Faria de Vasconcelos. Paedology. New School ideas.

\title{
Resumen
}

El estudio, de carácter histórico-descriptivo en el ámbito de la Historia de la Educación, aborda las suposiciones psicopedagógicas de la Pedología, que es la ciencia de desarrollo infantil fundada en la pedagogía, propuestas por el pedagogo portugués Faria de Vasconcelos. Analizaremos y reflexionaremos, teniendo como base la metodología hermenéutica, el contenido de aquellos aspectos en su obra y utilizando fuentes secundarias sobre esta temática. Este pedagogo, impregnado de los ideales del Movimiento Nueva Escuela, asociados a su experiencia en Bierges (Bélgica) aporta contribuciones al estudio científico de la infancia. Los dos puntos de la estructura del texto coinciden con los objetivos establecidos: analizar la Pedagogía basada en la Pedología, en el estudio del desarrollo del niño, basado en la pedagogía experimental; interpretar las suposiciones psicopedagógicas del crecimiento y la autonomía del niño, las funciones físico-psíquicas (principios: continuidad y solidaridad) y el humanismo antropológico. Vasconcelos es uno de los promotores de pedotecnia/psicotecnia y/o psicopedagogía en el estudio de escolares en la Historia de la Educación en Portugal.

Palabras clave: Faria de Vasconcelos. Pedología/Paidologia. Ideas de la Escuela Nueva. 


\section{Enquadramento prévio}

António de Sena Faria de Vasconcelos, insigne pedagogista português, nasceu em Castelo Branco (Portugal), filho do Procurador Régio da Comarca, Dr. Luiz Cândido de Faria e Vasconcelos e de $\mathrm{D}^{\mathrm{a}} \mathrm{M}^{\mathrm{a}}$ Rita Sena Bello de Vasconcelos, neto materno do conselheiro Simão Pedro de Sena Bello, formou-se em direito, seguindo a tradição familiar (MARTINS, 2019b). Desde cedo sentiu, fruto dos tempos, uma profunda vocação por outras áreas do conhecimento, especialmente a pedagogia, filosofia (social), a paidologia, a psicotecnia e pedotecnia, a biologia, a antropologia, a sociologia, as artes, a ética, etc., especialmente aquando da sua permanência na Bélgica e Suíça (1902-1915). Todos esses conhecimentos vão-lhe proporcionar a análise, a reflexão e interpretação dos factos, processos e problemas educativos/escolares e, daí a nossa referência no título de ter sido um 'polígrafo' de saberes da pedologia/paidologia do seu tempo, especialmente nas matérias relativas à criança/infância e adolescência. Para ele a Pedagogia (contemporânea) permitiu que os educandos tivessem uma educação integral, realizada harmoniosamente nas suas várias dimensões (FERNANDES, 2006).

A sua biografia vital e/ou percurso formativo apresenta momentos articulados entre si e suscetíveis de uma análise mais aprofundada, se bem que têm surgido vários trabalhos científicos em Portugal e Brasil nos últimos anos, por exemplo aos períodos: (1880-1902) formação primária em Castelo Branco, seguida no Colégio dos Padres do Espírito Santo em Braga e terminando com o curso de direito na Universidade de Coimbra; (1902-1912) formação académica na Universidade Nova de Bruxelas, sendo nela professor, para além de divulgador das ideias inovadoras na educação; (1912-15) o sentido prático da pedagogia (experimental) ao experimentar os princípios da Escola Nova em Bierges na Bélgica, seguido de uma ampliação de conhecimentos, de colaboração académica e partilha de ideias com figuras do Instituto J. J. Rousseau, em Genéve (Claparède, Ferrière, Bovet); -(19151920) desiludido com o ambiente de guerra parte na 'Missão belga' de pedagogos (contratados/convidados) para a América Latina (Cuba e Bolívia), onde intervém e aplica as ideias da Escola Nova; (1921-1939) de regresso a Portugal, dedica-se ao trabalho docente em várias instituições de ensino, participa em várias revistas (Seara Nova) e colabora na Proposta de Bases de Reforma do Ensino de João Camoesas, em 1923 (GOMES, 1980), para além da criação do IOP-Instituto de Orientação Profissional (1926-39), do Instituto de Reabilitação Mental e Pedagógico (1929-31), do Instituto Navarro de Paiva, onde foi um investigador exímio. Como diretor e professor no IOP que o seu nome ultrapassou fronteiras, projetando o nome da instituição de tal forma que foi uma das mais prestigiadas na Europa, como refere o editorial da La Gazeta Literária Iberico-Americana (1928, p.1):

La segunda conferencia, que tuvo lugar el domingo, fue pronunciada por el Dr. Faria de Vasconcellos, y versó acerca del Instituto de Orientación Profesional, que dirige con sumo acierto. Este Instituto es uno de los más modernos de Europa. La orientación profesional con 22 laboratorios, que sirven para orientar a menores y adultos, con arreglo a sus capacidades físicas y mentales, en la profesión que debe seguir. Posee este Instituto secciones fisiológica, psicológica, pedagógica, económica de colocación y protección del menor delincuente, y su esfera de acción se está alargando ahora hasta las escuelas públicas, para lo cual prepara el Instituto peritos especializados en estas delicadas materias. El profundo estudio de esta moderna institución ha despertado gran interés entre los pedagogos y hombres de ciencia que asistieron a esta conferencia. 
A obra de Faria de Vasconcelos apresenta uma perspetiva sistémica que necessita de uma releitura não só à luz do modelo da Escola Nova, dado que ele é mais génio que reflexo, mais produtor do que produto desses ideais escolanovistas (MARTINS, 2019b). Ele é um polígrafo no domínio dos saberes científico-pedagógicos, da época, e do fazer (ação), o que obriga aos historiadores da educação a uma profunda 'reconstrução' do seu discurso e da sua práxis. Se destacarmos a referência básica às 'Lições de pedologia e de pedagogia experimental' (VASCONCELOS, 1909; MARQUES, 1986, p. 187-692) e à 'Une École Nouvelle en Belgique' (VASCONCELOS, 1915, 2015), para além de outros escritos ilustrativos do seu pensamento educativo e psicopedagógico, podemos verificar a sua convicção no poder regenerador, emancipador e edificante da educação, na base da pedagogia científica. Essa tendência no seu pensamento fê-lo evoluir por interesses científicos sociológicos, pedagógicos (pedológicos) e psicológicos, os quais determinaram a sua atividade intelectual, sempre incidindo na formação dos professores e na capacidade transfiguradora da ação educativa.

Este escolanovista com ideais de pedagogia inovadora e científica colocou a ciência da educação ao serviço da ação e a ação ao serviço da grei, sendo um bom exemplo desta nossa afirmação o seu desempenho nas instituições que dirigiu, em especial o IOP, ao colaborar com as escolas na deteção e apoio aos alunos com dificuldades escolares ou de aprendizagem ('fracos de espírito'), incluindo as crianças/jovens 'anormais', como também na didática de formação do professor, de modo a intervir e apoiar os alunos nos problemas escolares. Apostando sempre pela inclusão colabora nos processos de diagnóstico da infância detida nas Tutorias Centrais de Infância (observação nos Refúgios), com as instituições de reeducação e serviços jurisdicionais de menores, com as instituições de assistência social e com as empresas com a finalidade de aperfeiçoamento profissional. Para ele a orientação escolar e profissional consistia em substituir os processos arbitrários e empíricos na escolha (vocacional) duma carreira/curso por métodos científicos, submetendo o indivíduo a um diagnóstico e a uma série de exames (clínico, fisiológico, antropométrico, mental ou cognitivo) "destinados a verificar não só as suas aptidões, como as suas inaptidões, a estabelecer o seu tipo somático, funcional e mental, as suas caraterísticas essenciais" (VASCONCELOS, 1931, p. 9). Nesta formidável formulação de orientação, fundamental no processo educativo/formativo dos indivíduos, incutia também a perspetiva ética profissional e/ou deontologia profissional, na linguagem atual.

O Diretor do Bureau International des Écoles Nouveles, A. Ferrière, atribui-lhe a designação de 'Pioneiro da Escola Nova', no prefácio do livro 'Une École Nouvelle en Belgique' (VASCONCELOS, 1915), experiência escolar onde cumpriu 28,5 dos 30 princípios das escolas novas propostos por aquele Bureau. O pedagogista português considerava que aquelas escolas 'Novas', não eram modelos da escola do futuro, mas sim o seu laboratório e, por isso, tinham o sentido experimental, de lugar de ensaio pedagógico (Escola Nova versus pedagogia experimental) e vocacionadas a transformar as escolas ditas tradicionais. Ora bem essa escola 'Nova' sendo o laboratório (científico) da educação (do futuro), estava sustentada em princípios ou pressupostos essenciais, tais como: o respeito pelas necessidades físicas, psíquicas e mentais da criança no seu desenvolvimento (leis da 'paidologia'- influência belga) e nas pré-disposições individuais, com a influência do meio envolvente (familiar, social, cultural e/ou educativo). Ora é nessa metamorfose de ideias da época, relacionadas com o estudo científico da criança e da sua infância, que aborda os seus aspetos psicopedagógicos do seu desenvolvimento, em especial, as suas funções físico-psíquicas e mentais ao nível escolar.

O nosso estudo, de cariz histórico-descritivo (metodologia qualitativa), no âmbito da História da Educação (Pedagogia contemporânea), elencado no método hermenêutico de análise ao conteúdo dos escritos sobre a pedagogia, pedologia, pressupostos psicopedagógicos de A. Faria de Vasconcelos (1909,1915, 1921a 1921b, 1925, 1928, 2015), recorrendo igualmente à sua obra organizada, em volumes, por J. Ferreira Marques $(1986,2006,2012)$ relacionados com a nossa temática de abordagem, para além do recurso 
a fontes secundárias de vária índole (MARQUES, 2012, MARTINS, 2017, 2019), referentes ao escolanovista em análise ou ao contexto pedagógico da época em que viveu. Procurámos, através dos objetivos propostos, entender melhor o pensamento de Faria de Vasconcelos, refletindo-o na vertente da Pedologia, a qual se fundamenta na pedagogia experimental e que teve no quadro das Ciências da Educação, um interesse específico para a formação dos professores normalistas e para a ação educativa. Neste período histórico, em que viveu Faria de Vasconcelos, a pedologia, a paidologia, a medicina (influxo da psiquiatria relativamente à 'anormalidade') e o higienismo (e eugenismo) (VELOSO, 2017) foram determinantes para conhecer a criança/infância e adolescência, para além de influírem no discurso político (políticas sociais/educativas).

\section{A Pedagogia norteada pela pedologia}

O escolanovista português, expressa a sua intenção e finalidade do respetivo conteúdo (12 lições proferidas) da obra 'Lições de pedologia e de pedagogia experimental, abordando a pedagogia fundada na pedologia, referindo que:

systhematisação e vulgarização que a muitos, apesar das suas imperfeições, pode ser útil. Numerosas indicações que n' ellas se contêm são de aplicação immediata e indispensável nas escolas actuaes. Outras supõem uma organização escolar inteiramente differente da existente. Mas tanto umas como outras obedecem a este princípio fundamental em Pedagogia: adaptação do ensino e da educação ao desenvolvimento natural, physico e psychico, da creança. (VASCONCELOS, 1909, p.7).

Vasconcelos define a Pedologia como uma ciência nova, numa vertente psicopedagógico e social (MARQUES, 1986, p. 198), ou seja, para ele "É a ciência experimental da criança sob os seus diferentes aspetos", que procura conhecer o corpo da criança, seja ela com desenvolvimento normal ou anormal. Esta nova pedagogia de índole experimental integrava saberes físicos, fisiológicos e psíquicos relativos ao desenvolvimento da criança, utilizando técnicas (instrumentos), de tal modo que Faria de Vasconcelos especifica essa definição dizendo: "A pedologia é a fisiologia experimental da criança, cujo corpo e espírito procura conhecer, tendo em vista a determinação não só das leis do seu desenvolvimento, mas também das diferenças, variedades e tipos individuais", de forma diferenciada (MARQUES, 1986, p. 205). Tratava-se de uma ciência nova, orientada ao "O estudo científico da criança está ainda muito atrasado e seria extremamente imprudente deduzir dos resultados atuais da psicologia experimental aplicações pedagógicas precisas e positivas" (MARQUES, 1986, p. 206).

O estudo científico da vida (desenvolvimento) da criança abrangia, segundo Faria de Vasconcelos "todos os problemas respeitantes à natureza física e psíquica da criança, cuja solução procura no sentido de uma pedagogia prática, de uma educação natural e lógica da criança" (MARQUES, 1986, p. 205). A Pedologia investigava o crescimento das crianças, durante o período da(s) infância(s), em que as teorias guiavam esses estudos, indicando experimentalmente o modo de "conduzi-la à plenitude do seu desenvolvimento" (MARQUES, 1986, p. 224) e, por isso, abrangia problemas relacionados com a preservação do crescimento da criança; problemas sobre os estímulos nas suas forças (vontade); problemas respeitantes a fatores conducentes ao seu desenvolvimento integral. Para Vasconcelos aquela ciência "investiga as leis gerais dos processos psíquicos, do desenvolvimento físico e mental da criança, trata de problemas de ordem geral: os resultados gerais são aplicáveis a todas as crianças" 
(MARQUES, 1986, p. 208). Considerada a ciência experimental da criança haveria que "conhecer o corpo da criança (estatura, peso, etc.) normal ou anormal, a sua evolução, os órgãos dos sentidos, o seu espírito, as qualidades e defeitos físicos, intelectuais e morais, tendo em vista a determinação das leis do desenvolvimento físico e mental" (MARQUES, 1986, p. 198). Competia aos professores "conhecer a natureza da criança e criar em volta dela um meio que seja conforme ao seu desenvolvimento" (VASCONCELOS, 1909, p. 47). Na escola, à semelhança do médico, o professor deveria estar capacitado para avaliar as condições de aprendizagem de cada aluno e encontrar, com estratégias adaptadas ao percurso educativo de cada um deles e, por isso, era importante conhecer a criança, pois, naquela época, a formação de professores estava "[...] nas mesmas condições em que se encontraria um homem que fosse horticultor sem ter noções de botânica que o habilitassem ao conhecimento das plantas" (VASCONCELOS, 1909, p. 10). Era óbvio que o professor deveria ter conhecimentos de currículo, estar habilitado a aprofundar outras áreas disciplinares do aluno, por exemplo, os aspetos anatómicos, antropológicos, fisiológicos, psicológicos, relações sociais e a relação da criança com o meio envolvente (PIMENTEL-FILHO, 1929).

$\mathrm{Na}$ verdade, a pedologia orientava-se pela perspetiva medico-pedagógica (MARQUES, 1986, p.194-195), com destaque para a intervenção do médico na escola. Historicamente a medicina repressiva e profilática foi alargando as suas funções a uma medicina preventiva (escolar), debruçando-se sobre o desenvolvimento físico da criança (FERREIRA, 2003). Passou a haver uma relação do movimento da Pedologia com o movimento higienista (higiene social, escolar), com a pedotecnia (passagem do empirismo para o campo científico em educação) (GERMÁN, 1955, p. 831), com a antropometria e a orientação (pessoal, social e profissional), que brotavam nos foros científicos da época na Europa e Estados Unidos (FIGUEIRA, 2004).

Este modelo médico-pedagógico constituía o fulcro da evolução da ciência da educação, segundo Faria de Vasconcelos (MARQUES, 1986, p. 191-197). Os métodos (experimentais) da Pedologia norteavam-se por mensurações (pedometria), por antropometria, anatomia e fisiologia, para além das observações, do uso dos métodos de introspeção, retrospetivo, psicanalítico, do método experimental e do método objetivo ou de extrospeção (MARTINS, 2019a). Toda essa amálgama de conhecimentos, de índole psicopedagógica (Paidologia), fez surgir institutos e figuras, entre outras a de Decroly na Bélgica, de Montessori na Itália, de E. Claparède (1910, 1960) e A. Ferrière (1955), no Instituto J. J. Rousseau em Genéve, que influenciaram não só Vasconcelos como muitos pedagogos portugueses (Aurélio da Costa Ferreira, Alves dos Santos (1917), A. Sérgio e Luísa Sérgio, etc.). A Pedologia continha uma divisão composta pelas nas seguintes partes (MARTINS, 2019a):

(a)-Pedologia Pura: pedagogia somática integrando a anatomia e fisiologia infantil; a pedologia psíquica composta pela estrutural, funcional e genética; e a pedologia médica integrando a patologia e higiene infantil. Esta pedologia abordava o estudo integral da criança (biologia, psicologia e sociologia infantil) descrevia o organismo infantil na sua estrutura, no desenvolvimento, no sistema nervoso (fisiologia e neurofisiologia), ao nível psicológico e respetivo funcionamento diferencial nas distintas idades ou períodos de evolução infantil (pedologia somática e psicopedagogia) (MARQUES, 1986, p. 205-212).

(b)- Pedologia Aplicada, que compreendia a pedotecnia educativa (psicopedagogia, higiene escolar e ortofrenia), pediatria ou pedotecnia médica (psiquiatria, clínica infantil e higiene infantil), a pedotecnia judiciária (criminologia infantil e profilaxia pedológica) e a pedagogia experimental (FERREIRA, 2014). Este tipo de Pedologia (também designada por Pedotecnia) utilizava-se em pesquisas práticas sobre os problemas da vida física, psíquica, social e patológica da infância. Na perspetiva educativa havia uma relação entre os objetivos da Pedologia com os da educação (intelectual, física e moral/social) e ação educativa, tendo em conta as leis e princípios fixados pela pedologia somática e psíquica. Esta influência no campo 
da educação originou a vertente da psicopedagogia (FERREIRA, 2014, p. 301). Assim, a pedotecnia educativa referia-se às condições higiénicas escolares (edifícios, material, aula, organização escolar, orientação, exercícios físicos, jogos, excursões, museus, cantinas escolares), de profilaxia social às doenças infetocontagiosas e parasitárias, inspeção sanitária escolar, auxílios escolares, etc. (GERMÁN, 1955).

(c)-Pedologia social ou sociopedologia incluía a pedotecnia judiciária, havendo uma convergência para o campo da pedagogia social, de índole alemã, ao estudar as causas mesológicas, educativas e psicológicas aos menores perigosos e/ou (pré) delinquentes e, em especial, inicialmente numa perspetiva correcional e, depois, reeducativa relacionada com o tipo de menores inadaptados (tipificados juridicamente 'em perigo moral' ou em risco: pobres, abandonados, desamparados, mendigos, expostos, etc.) (PIMENTEL-FILHO, 1929).

Todas estas especificidades da Pedologia e as suas divisões convertiam-na numa ciência totalizante de conhecimento sobre a criança/adolescente, fundamentando a compreensão do próprio desenvolvimento e orientando os educadores na tarefa educativa. A preocupação da pedologia em acompanhar as diversas fases desse desenvolvimento entre a irregularidade, a anormalidade e a normalidade (discursos de influência médicopsiquiátrica e higienistas) da criança/infância, analisava os fatores (des)favoráveis que sobre ela atuava, confundindo-se, por vezes, com a pedagogia experimental, mas sendo uma vertente psicopedagógica experimental (MARQUES, 2012). Os próprios dados obtidos por diagnóstico às crianças/adolescentes proporcionavam processos terapêuticos de intervenção (influência dos saberes da medicina articulados com os de paidologia da época) no seu crescimento, tornando inadiável a necessidade de observação e de exames pedométricos, em especial, às crianças escolares.

Relembramos que a base da educação e da Escola Nova era o estudo científico da criança, concebida como uma ciência natural (influência do naturalismo de Rousseau, Pestalozzi, Froëbel, entre outros) (GUICHOT-REINA, 2010). Era evidente que a Pedologia estava ao serviço dessa nova ciência cujo objeto de estudo era a criança, utilizando a metodologia experimental da observação e experimentação, com a criação de laboratórios (psicologia infantil) e instituições específicas, no início do séc. XX, por exemplo: o Instituto Médico-Pedagógico da Casa Pia de Lisboa, para sexo masculino, dirigido por Aurélio da Costa Ferreira (1920) e tendo um boletim de divulgação próprio; a Colónia de São Bernardino em Peniche, para sexo masculino dependente da Casa Pia; o Instituto Médico Pedagógico da Condessa de Rilvas, para sexo feminino ligado à Igreja; e o Instituto Adolfo Coelho). Deste modo multiplicaram-se as técnicas de mensuração, os inquéritos e outros exames de diagnóstico, inclusive ao nível escolar, incluindo os exames nas Tutorias Centrais de Infância (Refúgios em anexo) e reformatórios para menores (FONSECA, 1930), tendo o IOP, dirigido por Faria de Vasconcelos $(1928,1931)$, servido de suporte a muitos diagnósticos psicológicos, incluindo a delinquentes (relação com a mensuração da inteligência).

Além disso, a Pedagogia positiva pretendia a reintegração da criança na natureza (físiconatural, cósmica), considerando-a um elemento que foi afastada pela pedagogia teológica e pela pedagogia metafísica (GABLE \& HAIDT, 2005, p. 105). Ou seja, pretendia o respeito pela natureza da criança, em que o seu crescimento ou desenvolvimento, pressuposto da lei fundamental, exigindo uma adequada formação e qualificação do professor. Se o crescimento físico da criança era constituído como lei pedológica fundamental e como sintoma de (a)normalidade, então surgia o dever de conhecer para prever e prever para prover, convertendo o educador num higienista (influência na época em termos sociais e escolares) que "vigia e favorece o desenvolvimento normal da criança" (VASCONCELOS, 1909, p. 20). Esta obrigação de proporcionar um meio adequado ao crescimento e desenvolvimento normal da criança e da sua infância, considerada uma condição sine quo non dos escolanovistas, cabia ao educador/professor essa incumbência de tratar esses fatores, que são despertadores e 
estimuladores das energias físicas e intelectuais da criança que, no dizer de Faria de Vasconcelos (1909, p. 20) e seguindo as teses de Binet, "antes de ensinar e educar a criança, o educador precisa, primeiro que tudo, (...) ensiná-la a aprender". Daí que os fatores propícios ao crescimento fossem a ginástica física (pedagógica) e intelectual, os exercícios e trabalhos manuais, os jogos escolares e a parte lúdica do aprender, a música, as lições das coisas, as caminhadas, excursões, visitas pedagógicas, etc.

Devemos referir que a Pedologia foi ensinada entre nós no âmbito da formação de professores, em Lisboa, por exemplo na Escola Normal do Calvário por Costa Sacadura em 1908-09; por A. Faria de Vasconcelos proferindo 12 lições na Sociedade de Geografia de Lisboa, em 1909-10, quando era professor na Universidade Nova de Bruxelas; e mais tarde por Aurélio da Costa Ferreira (1921) e Alberto Pimentel Filho (1929) na Escola Normal de Lisboa, tal como mais tarde Fernando Palyart Pinto Ferreira abordando as crianças 'anormais'. Houve muitos outros médico-pedagogistas interessados na compreensão do desenvolvimento da criança e/ou infância e adolescência, pois estavam convictos, numa necessidade de especialização e de cientificidade de modo a preparar a criança ou indivíduo para a vida (FERREIRA, 2014). O conhecimento da evolução do crescimento da criança/adolescente permitia orientar o seu processo educativo, na convicção que a educação como a ciência emergente sustentava a ação educativa do educador/professor e poderia transformá-la. As diferentes abordagens da Pedologia (pura, aplicada, social), tal como é referida por Vasconcelos, permitia psicologicamente orientar a ação educativa dos professores, sabendo que aquela ciência se vinculou à medicina que, desde o higienismo (social, escolar), se expandiu e se legitimou na intervenção pedagógica e também abarcando os problemas de saúde, compreendidos como problemas sociais e urbanos e com repercussão nos problemas escolares.

Historicamente a paidologia e/ou a pedologia (de índole francófona) tomou a influência da medicina (psiquiatria, pediatria) para interpretar a normalidade versus anormalidade ou patologias, recorrendo aos critérios de avaliação psicopedagógica e psicossocial (MARTINS, 2017). Complementarmente a Pedologia tomou do higienismo o modo de intervir nos problemas práticos, a partir dos conhecimentos científicos da época, legitimando a extensão do seu campo à educação/ensino (higiene escolar), à criminologia infantojuvenil, à puericultura e à interpretação da sociedade e da história (FERREIRA, 2014). Assim, o modelo médico-pedagógicos e/ou modelo médico-biológico incidiram a sua interpretação nos problemas de anormalidades ou doenças mentais e das condutas das crianças/jovens em desviação social, em geral, em especial a vagabundagem, a pobreza, a marginalização, a delinquência e criminalidade (VASCONCELOS, 1931). Ou seja, a expansão desse modelo e do higienismo acompanhou a visibilidade que tiveram os problemas da questão social, nos finais do séc. XIX e princípios do séc. XX.

Por conseguinte, Faria de Vasconcelos considera em termos psicopedagógicos, aspetos fundamentais da Pedologia (MARQUES, 1986, p. 205): importância da adaptação do ensino à fisiologia e a psicologia infantil; a promoção e multiplicação das relações entre 'FamíliaEscola', de modo a motivar os pais para o percurso escolar dos filhos; associar o médico à educação mental (colaboração); formar o professor à (re)organização do ensino em novas bases com métodos e estratégias ativos; criar laboratórios na escola e levar os alunos a realizar experimentos, com o apoio pedagógico do professor, fazendo o aluno embrenhar-se em conhecimentos e fazer aplicações pedológicas no seu aprender. Ora os problemas da Pedologia abrangiam a preservação do crescimento da criança, o estimular as forças físico-psíquicas dela, ensinando-lhe a promover a aquisição de saberes, em função do seu estado/fase de evolução físico-psíquica e, para isso deveria utilizar-se métodos quantitativos e qualitativos, os métodos de análise e/ou síntese (testes, escalas). 


\section{Pressupostos pedológicos no sistema vasconcelosiano}

O estudo científico da criança/infância, inserido na paidologia e pedologia, de origem essencialmente francófona, apresentava vários princípios ou pressupostos científicos, assinalados por Faria de Vasconcelos (1909, p. 12), como caraterísticas da Pedagogia (contemporânea), considerada a Ciência da Educação, nos finais do séc. XIX e princípios do XX (VASCONCELOS, 1921, p. 17) e que iremos em seguida analisar.

\subsection{Pressuposto pedológico do crescimento da criança}

Na obra 'Problemas Escolares' o escolanovista português refere o espírito científico, a metodologia de análise às caraterísticas da educação contemporânea, em que a Pedagogia, como sendo uma "ciência autónoma", em consenso com a "meta-narrativa positivista", entrou "na fase do método científico, libertando-se do empirismo" (VASCONCELOS, 1921, p. 13) Deste pressuposto ou princípio da Pedagogia e/ou da Escola Nova decorria o imperativo essencial da "educação psicológica e pedológica do professor", tão essencial ao ato pedagógico de educar (VASCONCELOS, 1909, p. 12). Ora bem, este pressuposto (psico)pedagógico já tinha sido referido por pedagogos antecedentes da Escola Nova (Rousseau, Pestalozzi, Fröebel) ao alertar do desconhecimento do educador pela forma de ser e caraterísticas do educando. O pedagogista português preconizava a submissão dos conteúdos curriculares (unidades de aprendizagem) e da processologia didascálica às necessidades e capacidades individuais psicofísicas da criança no contexto escolar. Assim, a Pedologia, baseada na metodologia experimental da observação e experimentação recorreu à mensuração de aspetos decorrentes do processo escolar da criança. Ora bem o conhecimento dos sintomas de (a)normalidade no desenvolvimento dela convertia o professor/educador num higienista que "vigia e favorece o desenvolvimento normal" e lhe cria um meio propício (VASCONCELOS, 1909, p. 20) e, por isso, cabia-lhes cuidar desses fatores relacionados com as energias físicas e intelectuais (na base das ideias de Binet).

Faria de Vasconcelos considera o professor como um 'investigador', hoje diríamos investigador reflexivo sobre a sua própria ação (pensamento), um conhecedor das leis da Pedologia geral, das diferenças e aspetos revelados por ela, para além de estar atento à sua sensibilidade e imaginação, à atenção, à memória, ao juízo, à reatividade, etc. A emergência desta (nova) ciência da educação fez surgir, na época (influência científica) a preocupação por um novo objeto científico de estudo (WAGNON, 2013): o crescimento da criança/adolescente na base de leis (desenvolvimento), utilizando o método experimental de abordagem. Todo este cenário fez refletir a função do educador/professor sobre a "preservação da evolução normal da criança" (VASCONCELOS, 1909, p. 33), numa abordagem científica e de medição (observação, técnicas, métodos, exames e testes) relativamente ao seu crescimento físico e intelectual (VASCONCELOS, 1925). Neste sentido, nota-se a influência de Binet, Decroly, Claparède, G. Rouma, G. Compayré, E. Peeters, entre outros, e ainda por Quetelet e Schuyten em termos antropometria escolar. Na nossa perspetiva a 'vigilância' do professor sobre o crescimento físico-psíquico da criança exigia o uso da pedometria, pois segundo Faria de Vasconcelos (1909, p. 39) "permitia saber em cada caso individual se o desenvolvimento da crianças se faz normalmente ou se é muito rápido ou se está atrasado", retardado ou com dificuldades em aprender, para além da ajuda dos dados antropométricos que indicavam "a determinação do género e da quantidade de exercícios físicos que é preciso aconselhar".

Além disso, a mentalidade da criança modifica-se, cresce, desenvolve-se evolui, de tal forma que esse desenvolvimento se realiza por uma diferenciação gradual das experiências mentais, por um progresso na sua organização no controlo pessoal (MARQUES, 1986, p. 287289). Para o escolanovista português a educação mental para assegurar as condições mais favoráveis ao crescimento, ao desenvolvimento da mentalidade, no sentido da sua diferenciação 
e organização, deveria cultivar e adestrar as funções e processos mentais destinados a adaptar a criança ao meio, às variações e modificações que ela ia sofrendo e às novas situações que lhe surgissem. Ora o desconhecimento da natureza psicofisiológica da criança (escolar), das suas tendências, capacidades e atividades, das caraterísticas e diferenças deviam ser analisadas pelo professor de modo a ele estabelecer a orientação adequada do ensino a dar-lhe.

De facto, essas observações e medições (pedometria) deveriam, segundo Faria de Vasconcelos (1922, p. 20), obedecer a um quadro de análise que tivesse em conta: os ritmos do crescimento com as fases ao longo dos anos da infância; o crescimento diferencial dos diversos órgãos; um longo período de crescimento em relação ao dos outros animais. Nesta evolução era possível detetar uma 'correlação inversa' de crescimento físico e a energia mental, sabendo que a aptidão intelectual decrescia nos períodos de crescimento rápido, o que provocava determinadas implicações pedagógicas:

O ensino e pedagogia atual revelam o desconhecimento, quase absoluto, destas questões fundamentais e vitais. É preciso adaptar o ensino, a pedagogia, a fisiologia e a psicologia da criança, de modo que a organização escolar, os horários, os programas, as aulas e as férias se inspirem das exigências e das necessidades do corpo e do espírito infantis. (VASCONCELOS, 1909, p.85)

Os dados obtidos no diagnóstico proporcionavam uma intervenção terapêutica e, daí a necessidade de exames pedométricos nas escolas, principalmente sobre a estatura, o peso, o perímetro torácico, diâmetro biocromial, a cefalometria, a força muscular etc. Uma das medidas propostas por Vasconcelos era a elaboração da caderna escolar preconizada pela vertente médico-pedagogista da Escola Nova, que facilitava ao professor "o conhecimento da marcha do crescimento físico e do desenvolvimento mental da criança" numa normalidade evolutiva higiénico física e psíquica (VASCONCELOS, 1909, p. 86). Além deste principio pedológico do desenvolvimento, Faria de Vasconcelos mencionava, referindo-se a vários estudiosos da época as seguintes leis: lei biogenética pela qual as crianças se desenvolvem na mesma ordem da espécie (fases); lei de Pestalozzi em que a lei absoluta do espírito a ascensão da intuição ao abstrato era restritiva, já que se referia à instância cognitiva; a lei de Stern que, sendo reducionista, sintetiza a evolução pedológica da periferia para o centro (da heteronomia para autonomia). Para ele o desenvolvimento mental era complexo para ser explicado por uma só lei e, assim, recorrendo a Claparède (1910) indica várias leis pedológicas mais harmoniosas, por exemplo: a lei da sucessão genética em que o processo desenvolvimento mental se efetua por fases sucessivas e constantes, em que a aquisição da relação temporal precede a assimilação da relação espacial; lei do exercício genético e funcional em que o jogo tem muita importância; lei da adaptação funcional relacionadas com o funções psíquicas . Ou seja, as inclinações naturais, os interesses e as necessidades psicológicas das crianças devem ser abrangidas pelo currículo, pelos métodos e atividades das crianças em termos escolares, para além de se conhecer as caraterísticas do desenvolvimento mental, assim como as diferenças intelectuais e morais e aptidões pessoais (lei da individualidade). Daí que o crescimento físico e a evolução espiritual (lei do ritmo) não se processam de modo contínuo, mas com avanços e com recuos.

\subsection{Pressuposto da autonomia a desenvolver pela criança}

No aflorar da nova ciência, a Pedologia, impõe a lei de autonomia da criança, que representa uma rutura com a teoria antropológica de que a criança é um adulto em miniatura e a infância uma fase instrumental da ascensão à maturidade. Deste modo a infância, considerada um estado autónomo da vida do indivíduo, era legitimada pela teoria e prática da educação e da 
Escola Nova. Não era o estado de adulto ou a maturidade que dava sentido à infância e/ou à adolescência, sabendo que a criança é uma unidade/totalidade em si. O reconhecimento do princípio de autonomia determinava a superação da conceção da criança à imagem e semelhança do adulto e a subordinação do ato educativo aos seus interesses específicos. A Escola Nova pretendeu acabar com esse "pré-juízo do adulto" (VASCONCELOS, 1909, p. 330). Assim, o escolanovista português, baseado em investigações, estabelece na criança três fatores no seu desenvolvimento mental: o jogo (parte lúdica), a imitação e o interesse.

(a)-Jogo. Este fator encerra uma profunda significação constituindo um alto grau do desenvolvimento infantil, sendo o "primeiro instrumento de desenvolvimento próprio da criança" (VASCONCELOS, 1909, p. 89), já que as atividades lúdicas eram atividades sensórios-motores. Recorre a várias teorias para explicar as vantagens do jogo infantil, por exemplo (MARQUES, 1986, p. 290-292): as teorias do recreio (Schaller, Lazarus, Guts Muths); teoria do excesso de energia (Schiller, Ruyssen); a teoria do ativismo (Stanley Hall); a teoria do exercício preparatório (Spencer, Wundt, Gross) em que o jogo é uma preparação para a vida; a teoria de Carr (exercício preparatório e de estímulo dos órgãos, da solidariedade e de descarga das tendências); a teoria de Lange (jogo implica o surgimento tendências latentes); a teoria de Claparède (1910) onde trata do desenvolvimento mental e físico, do jogo, da imitação, do interesse (psicobiológico) e da fadiga. Faria de Vasconcelos reconhece a multiplicidade de funções do jogo no desenvolvimento (físico-psíquico, mental, individual, social), mas distingue dois aspetos: o aspeto genético (pré-exercício da vida); e o aspeto físico (afirmação da personalidade perante as adversidades). Ou seja, para ele "o jogo é mais do que um passatempo, é também um trabalho intelectual e, por consequência, uma escola de pensamento e de vontade" (VASCONCELOS, 1909, p. 93). Desde a panóplia de jogos de imaginação, motores, intelectuais, afetivos, de exercitação da vontade e da atenção, da hereditariedade, de imitação, os artísticos, etc. todos eles ilustravam o facto de que os jogos se prendem entre si, quanto á origem e função educativa e ao predomínio acentuado de certos elementos constitutivos e fins particulares (MARQUES, 1986, p. 298).

(b)-Imitação. Este processo está ligado à sugestão, ao hábito ou ato voluntário, ou seja, ao reproduzir um ato de outro ou outrem. $\mathrm{O}$ ato de imitação para o ser necessita da condição de ser, como todo o ato humano (consciente e voluntário) e se for involuntário é provocado pelo contágio mental. $\mathrm{O}$ fenómeno da sugestão na época relacionava-se com a educação, já que a criança interiorizava inconsciente e involuntariamente a mensagem simbólica recebida. $\mathrm{Na}$ perspetiva de Binet a sugestão era a pressão moral que a pessoa exercia sobre a inteligência, a afetividade ou vontade, em que a palavra constituía a expressão frequente dessa influência (FERREIRA, 1920). Sabemos que a teoria de Bandura modificou essa conceção da imitação social, mas o que era sugerido pelos escolanovistas era a diferença entre o ato educativo o ato de sugestão, pois Faria de Vasconcelos (1909, p. 99) clarificava essa confusão pedagógica recorrendo a Vigouroux, Jacquelier, Guyau e até Gustave Le Bon ao dizer que "educador, cuja missão consiste em desenvolver inteligências e não em escravizar vontades, precisa de ter consciência do seu prestígio, a fim de resistir ao desejo de fazer obra de sugestionador". É óbvio que escola e os professores são estimuladores das funções psíquicas da atenção, vontade, da inibição e resistência da criança à sugestibilidade.

De facto, a inteligência é a função do organismo, mas sendo um fenómeno complexo estava submetido, na época, à métrica dos testes, já que os processos ou atrasos na criança (escolar) dependiam de fatores psicológicos, físicos, fisiológicos e pedagógicos (PINELL, 1995). Para Vasconcelos essa apreciação não podia recorrer a um único método, já que o corpo e o espírito combinam-se numa síntese harmoniosa e é pela exploração (diagnóstico) completa que se deveria determinar o valor intelectual do indivíduo (MARQUES, 1986, p. 264). Cabe à escola introduzir a prática dos exames (psicológicos, pedagógicos, anatómicos e fisiológicos da criança e, além disso, adaptar o ensino/educação ao grau do desenvolvimento intelectual e físico 
dos alunos (MARQUES, 1986, p. 565). Ou seja, era fundamental criar à volta da criança um meio correspondente às suas necessidades de desenvolvimento, de modo a garantir-lhe a sua evolução natural e preservá-la dos fatores de perturbação ou anormalidades, os quais contrariavam essa regularidade física, intelectual e moral.

(c)-Interesse. Este fator, já mencionado por Herbart, W. James, Dewey, Claparède, Luquet, Decroly, entre outros, era determinante para o ensino da criança, constituindo um princípio chave na nova pedagogia no respeito ao seu desenvolvimento natural físico-psíquico (VASCONCELOS, 1909, p. 105). Conhecer a natureza da criança, os seus interesses e a condição de ajustamento dos conteúdos curriculares a ela, por parte do professor, tendo em conta a sua curiosidade e interesses, de modo a ter um bom desempenho escolar e, por outros lado êxito na ação educativa. Baseado em Claparède (1960), o escolanovista português referese, segundo a idade, aos seguintes interesses na criança: os percetivos ou sensoriais, os glóssicos, os intelectuais, os objetivos e os especializados. Além disso, os efeitos do interesse, segundo Vasconcelos (MARQUES, 1986, p. 310) e seguindo a Claparède (1910) seriam: o aumentar a intensidade e nitidez da perceção, através da adequação dos sentidos e da atitude do corpo; a reação do organismo ao objeto que o impressiona, é acompanhada por um sentimento específico, que sustenta a perceção (sentimento do interesse) de um sentimento de prazer ou dor; aumenta a intensidade da perceção pela ação dinamogénica sobre os centros nervosos, já que a adaptação apropriada à excitação interessante prevalece sobre as adaptações possíveis. Daí que Vasconcelos (1925, p. 22-26) abordasse os interesses infantojuvenis recorrendo às teses de Baldwin, Luquet, Claparède, entre outros, pois considerava que as tendências naturais, adquiridas (hábitos) apresentavam uma intensidade de impressão em que o conteúdo e o dinamismo da consciência e os fenómenos do organismo eram fulcrais.

\subsection{As funções psíquicas e os princípios da continuidade e solidariedade}

Os princípios de continuidade e solidariedade acompanham as funções psíquicas, já que estas "são solidárias, interdependentes" (VASCONCELOS, 1909, p. 115). A indistinção ontológica dos fenómenos físico-psíquicos decorria da unidade do 'dinamismo psíquico' que se diversificava numa multiplicidade de funções. Ou seja, a função do organismo, em termos da explicação da psicologia, da biologia ou ciência natural das funções psíquicas determinava: a continuidade psicofísica que diferenciava os fenómenos físicos e psíquicos em grau de desenvolvimento, intensidade e complexidade, expressões diferenciadas do processo evolutivo, tal como afirma Faria de Vasconcelos (1909, p.115):

Não há fenómenos afetivos que sejam só afetivos, fenómenos representativos que sejam só representativos. Qualquer fenómeno psíquico é ao mesmo tempo afetivo, representativo e ativo; o que distingue um fenómeno afetivo é o predomínio do elemento afetivo, na dosagem da combinação em que entram os outros elementos.

De facto, os pressupostos antropológicos da continuidade e solidariedade psicofísicas realizam-se na intenção pedagógica que ensinando uma função psíquica atuava-se sobre outras, já que a "atividade dos sentidos constitui a base da atividade psíquica" (VASCONCELOS, 1909, p. 119), tal como a relevância da educação sensorial nesse desenvolvimento. Por isso, em termos escolares os trabalhos manuais adquiriam uma valorização de formação para a cidadania no currículo, não sendo o meio, mas sim como finalidade pedagógica de contribuir para esse desejado desenvolvimento psíquico e moral da criança/jovem. A própria 'cultura integral' está subjacente a estes pressupostos da continuidade e solidariedade das funções psíquicas e da atividade orgânica, implicando um questionamento, na época, à luz da biologia, fisiologia e 
psicologia experimental de que essas aquisições constituíam uma unidade, já como sabemos o cérebro pensa e todo o corpo atua e sente (VASCONCELOS, 1925).

Na verdade, o escolanovista português destaca a educação física e sensorial na educação intelectual, no seguimento da psicologia genética piagetiana, pois para ele "os sentidos são os primeiros instrumentos do conhecimento" (VASCONCELOS, 1909, p. 137), o que determina o imperativo pedagógico da cultura e educação sensorial, a necessidade de exames médicos e físicos, que eram aspetos fulcrais para o professor/educador. Igualmente, este devia conhecer o tipo da memória e da complexidade das suas funções na aquisição dos saberes e a adaptação do ensino à natureza da criança, pois todos eles têm repercussão no desenvolvimento global da criança. Sabemos desde a teoria dos passos formais de Herbart que a associação de ideias é crucial no ensino. Faria de Vasconcelos critica as teorias de James e Stuart Mill, Bain, Bell e Spencer, baseadas no princípio da atração psicológica, já que não são só os fenómenos representativos que se associam, mas também os afetivos, e porque os factos percetivos não corroboram a originalidade das sensações, pois estas são produto da análise. Daí ser primordial os professores organizarem o ensino e a educação através de um sistema de associações em conformidade com a realidade psíquica da vida infantil.

Recorrendo a várias teorias sobre a atenção na criança/infância (Kulpe, Binet, Lange, Muller, Wundt, Ribot, James, Baldwin, Marrillier, Rignano, Rageot, etc.) o escolanovista português considera-a como o "fator primacial das operações psíquicas" (VASCONCELOS, 1909, p. 209), pois considera a interdependência do desenvolvimento físico, intelectual e moral. De facto, "A atenção é antes de tudo direção do pensamento", pois a "atenção é a espera" (atenção expectante) que tem como condições os interesses e tendências do indivíduo (VASCONCELOS, 1925. p. 14). Os fatores da atenção (interesse, jogo, atividades) alertam para a natureza da criança e a atração que os saberes ensinados, os métodos e os meios exercem sobre a criança (VASCOCNELOS, 1925, p. 11-13). Os escolanovistas organizam as atividades em função dos interesses e da natureza da criança e, por isso, a atenção, como função específica obedece aos mesmos princípios da unidade e solidariedade de todas as funções psíquicas, o que implica a conexão relacional entre o desenvolvimento físico, sensorial e intelectual com a atenção (MARQUES, 1986, p. 499). Estimular na criança a curiosidade e o interesse, adequados à natureza da criança e ao tipo dos saberes ensinados, com recurso a atividades sensoriais e percetivas, constitui o princípio e método da educação da atenção. Na verdade Vasconcelos (1909, p. 241) distingue a pedagogia do esforço da pedagogia pelo interesse, pois para ele:

Não é o educando pelo esforço que se educa o esforço. A educação pelo esforço cansa, fatiga e aborrece a criança e é esse sistema que se utiliza habitualmente. Não é fatigando a criança, impondo-lhe exercícios impróprios d sua idade que se fixa e mantém a sua atenção.

Por outro lado, a alternativa ao esforço na criança seria o interesse e a motivação (direta ou indireta), que constituem o modo da fixação e da duração da atenção. Assim, na base da autonomia da criança e da unidade e solidariedade das funções psíquicas que Vasconcelos concebe a função psíquica da inteligência (MARQUES, 1986, p. 322). Impunha-se à escola um imperativo pedagógico de examinar os alunos (exames anatómicos, fisiológicos, psicológicos) e adaptar o currículo ao seu nível de desenvolvimento psicofísico, ou seja, no sentido piagetiano, o conhecimento psicogenético seria a condição necessária dessa organização curricular. Todo o ensino acompanhava a evolução normal da vida físico-psíquica.

No que diz respeito à educação da afetividade, que hoje em dia seria a dimensão afetivoemocional do ser humano, na relação com as outras funções psíquicas (memória, atenção, inteligência) a atitude do educador/professor seria a de favorecer o próprio desenvolvimento da criança. Partindo da classificação dos fenómenos psíquicos (intelectivos, afetivos, ativos) revela 
o papel da afetividade que na sua perspetiva é "indispensável para levar a cabo nas melhores condições a educação intelectual. A ideia e a vontade tiram da emoção e do sentimento a sua força. Os prodígios da inteligência e os milagres da vontade é a sensibilidade quem os suscita e os cria" (VASCONCELOS, 1909, p. 332). Lembramos que Vygotsky (1979, p. 188) associava a afetividade ao pensamento, já que "para compreender a fala de outrem não basta entender as suas palavras - temos de compreender o seu pensamento. Mas nem mesmo isso é suficiente também é preciso que conheçamos a sua motivação".

Ora bem conhecer a natureza da criança/infância, a superação do pré-juízo do adulto e a criação de um meio propício ao seu desenvolvimento eram imperativos determinantes propostos pela Escola Nova. Da união dessa amálgama de condições obedecia a opção de privilegiar a persuasão, a recompensa e o reforço positivo, a coação, a intimidação, o terror, a punição, sabendo que o défice de conduta da criança não era oriundo da sua má vontade, mas sim das condições precárias orgânicas, do ambiente familiar e do desenvolvimento insuficiente intelectual e afetivo (MARQUES,1986, P. 353). A solução pedagógica para Vasconcelos (1909, p. 331) seria o de "animar a criança na sua luta de paciência para a descoberta do mundo"

Nesse seguimento de conhecer o desenvolvimento da criança surgia a atividade dela, segundo a educação ativa proposta na vertente do movimento da Escola Nova. Faria de Vasconcelos (1909, p. 335) relaciona-a com o princípio da unidade e solidariedade referida das funções psíquicas, considerando que "a atividade é um fenómeno inseparável dos outros fenómenos psíquicos", numa conexão que em geral "todo o estado de consciência é ao mesmo tempo afetivo, intelectual e ativo", residindo a diferença na proporcionalidade dos elementos intervenientes. É verdade que na atividade sobrepesam os reflexos, os instintos e os hábitos, mas para ele privilegiava a vontade (educar a vontade), a qual coligava com a do caráter (MARQUES, 1986, p. 634-637).

O escolanovista português diferencia o fundo primitivo natural (inato) da vontade, que provinha da herança específica e individual e da estrutura comportamental adquirida pelas influências exógenas (sociais, físicas ou morais) a que a criança estaria sujeita. Esta complexa função psíquica, quando condicionada por um leque de elementos (instintos, automatismo psicológico e hábitos) a educação pouco podia fazer. Na diferenciação de anormalidade no desenvolvimento da criança, aquele pedagogista, sob o influxo das ideias de pedagogos francófonos na época da sua estadia formativa na Bélgica e Suíça (Decroly, Schuyten, Claparède), distingue o estado patológico da fadiga ('surmenage'), nas suas manifestações díspares dos seus sintomas (vista, congestão cerebral, dores de cabeça, hemorragias nasais, vertigens, fastio, digestões difíceis, fraqueza, nervosismo e aborrecimento), que era provocado pelo trabalho desinteressado ou desmotivador da criança na escola (MARQUES, 1986, p. 660-668). A etiologia física da fadiga, sendo ele era devido à desnutrição, falta de exercícios físicos, imobilidade, hereditariedade e educação familiar, condições sociais e o excesso de matérias de ensino. Ao professor cabia-lhe, nas bases científicas da Escola Nova (psicologia genética), saber o que a criança podia fazer "conformando-se às prescrições de uma higiene física, moral e intelectual cuidada e científica" (VASCONCELOS, 1909, p. 400) e adaptando o ensino ao nível de desenvolvimento dela de modo a progredir de forma são e integral.

Por conseguinte, a genialidade pedagógica do nosso pedagogista residia na sua análise crítica de algumas ideias e teorias em voga na época, por exemplo, a lei biogenética que para A. Ferrière (1955) era um absoluto enquanto para Vasconcelos era relativa, tal como na relevância da lei de autonomia da criança e nas leis complementares da unidade e solidariedade das funções psíquicas. A continuidade versus descontinuidade no processo evolutivo da criança elucida-nos quanto à continuidade de muitas mudanças ocorridas no desenvolvimento gradual, apesar de algumas descontinuidades, mas tendendo a um aperfeiçoamento proveniente da educação e da ação dos professores. Esta ação de ensinar, 
deveria ser cientificamente organizada e relacionada com as necessidades do aprendizado, sendo imprescindível que o professor tivesse conhecimentos sobre essa relação 'ensino desenvolvimento', baseando-se em atividades adequadas a cada etapa do desenvolvimento da criança (MARQUES, 2012).

\subsection{O pressuposto básico do humanismo pedológico/antropológico}

O humanismo pedagógico-antropológico de Vasconcelos está bem patente no seu ideário de participação, intervenção e publicação, por exemplo, na Revista Seara Nova, na qual não esgota o seu pendor científico, idealista e 'regenerador', já que este ideário seareiro tinha um pendor iluminista, racionalista e crítico. Ele defende um humanismo integral bem evidente no seu pensamento pedagógico, pois a 'cultura integral' decorrente do sistema vasconcelosiano, relaciona-se com a formação (curricular) dos professores normalistas e com a apologia às virtudes pedagógicas e antropológicas essenciais ao exercício da profissão de ensinar como de realização de um ideal de vida e prática de virtudes cívico-sociais. A matriz epistemológica e pedagógica da sua ação e práxis constitui um influxo de naturalismo pedagógico (influxo de Rousseau e Pestalozzi) (MARTINS, 2019b). Para ele criança é concebida como um fragmento da Natureza e regulada pela lei do crescimento ou desenvolvimento físico, intelectual, social, moral, sexual, estético, ou seja, por um desenvolvimento integral de todas estas dimensões presentes no ato de educar (SANTOS, 1919). Esse naturalismo aberto, coincidente com algumas tónicas do discurso pedagógico republicano oficial, que defendia a ideia de a criança ser reintegrada na natureza (FIGUEIRA, 2004).

É bem patente em Vasconcelos a primazia que dá ao elemento físico no crescimento e/ou desenvolvimento do ser humano, quer na sua obra, quer na experiência na Escola Nova de Bierges (VASCONCELOS, 1915, 2015), quer ainda na sua atividade no IOP e na mundividência educativa da Proposta de Reforma de João Camoesas em 1923, isto é, na profundidade que dá à psicologia/biologia da intuição ou em temáticas relativas aos problemas escolares (VASCONCELOS, 1921a). No Prefácio da obra 'Lições de Psicologia Geral' declara que a construção teórica do que expressam essas lições "assenta previamente sobre a realização das experiências e observações que é possível fazer para a melhor compreensão dos fenómenos" (VASCONCELOS, 1925, p.7) relativos às funções psíquicas (atenção, hábito, memória, associação, consciência e o inconsciente (várias teorias explicativas e as suas relações com a consciência, especialmente a teoria de Janet, Jastrow, Freud, de Bazaillas, Binet, etc.). Neste sentido, de conceção do inconsciente, como aliás à consciência, o escolanovista português nega o caráter substantivo de realidade existente 'per se', considerando este constructo um qualificativo de determinados processos psíquicos, tal como a consciência é qualidade de outra modalidade de fenómenos (MARQUES, 1986).

Efetivamente Vasconcelos defende a existência de uma única e mesma atividade psíquica, que se manifeste nas circunstâncias de vida, sob a forma de atividade consciente ou inconsciente, dispondo ambas dos mesmos recursos, lembranças, recordações, imagens, ideias, experiências e funções (VASCONCELOS, 1925, p. 408). Partindo dos princípios da unidade e solidariedade das funções ou fenómenos psíquicos considera que o inconsciente ou subconsciente não se reduzem a simples processos cognitivos, afetivos, motores, já que era melhor considerá-los como um 'capital' de forças/energias afetivas, motoras e intelectuais. Ou seja, estas duas instâncias psíquicas (inconsciente, subconsciente) poderiam explicar de uma forma ativa a invenção, a imaginação criativa, a intuição ou as descobertas espontâneas, pois ambas se concebem, não puramente afetivas, mas como uma 'corrente de ideação', fluxo para formação de ideias, dinamismo de possibilidades e virtualidades intelectuais. 
Relembramos que, na época de Faria de Vasconcelos, a dicotomia 'hereditariedadeambiente', que provocou muitas discussões e publicações até à atualidade, fez surgir várias teorias sobre o desenvolvimento da criança, como por exemplo: a teoria psicanalítica de S. Freud; a teoria da recapitulação de Anna Freud; a teoria psicossocial de E. Erikson; a epistemologia genética de J. Piaget; a psicologia histórico-cultural de L. S. Vygotski; psicologia genética de $\mathrm{H}$. Wallon; etc. Todas estas teorias implicaram um marco conceptual que nos remete para o crescimento, a mudança, a continuidade, as etapas/estádios, as interações, o conhecimento, a ação, entre muitos outros termos, na tentativa de entender esse desenvolvimento humano e, daí as distintas conceções sobre os fatores destacáveis nesse processo, por exemplo: o inatismo (os eventos ocorridos após o nascimento não são relevantes); empirismo ou ambientalismo (a força do ambiente como fator de intervenção); o interacionismo (são múltiplos os fatores constituintes), entendendo o indivíduo como ser ativo e interativo no mundo sob diversas influências na sua trajetória. A outra polémica no desenvolvimento da criança/infância, que mereceu igualmente discussão científica era a conceptualização de 'anormal' e 'anormal' ou patológico (MARTINS, 2017), que no caso da 'anormalidade', com influência dos discursos médicos serviu de instrumento de controlo social aos comportamentos (pensamentos, sentimentos) de situações de certa infância/adolescência, proveniente de determinadas camadas da sociedade.

Portanto, a representação pedagógica/antropológica é muito mais ampla de abertura que o enunciado dos princípios que tratamos anteriormente, não se esgotando nas manifestações fenoménicas do dinamismo psicofísico. Sabemos que as finalidades da educação e do ser humanos, os valores (dimensão axiológica) e os ideais definidos e caraterizados por Vasconcelos, sob o influxo psicopedagógico, manifestaram-se na sua ação e intervenção na sua vida em terras Latino-americanas (na defesa da população indígena na Bolívia a favor de uma multiculturalidade solidária) e depois em Portugal, a partir de 1920 (MARTINS, 2019b).

\section{Ideias a reter...}

Abordámos os imperativos psicopedagógicos subjacentes às caraterísticas da pedagogia contemporânea fundada na pedologia (VASCONCELOS, 1921b). Esta ciência dedicada ao desenvolvimento da criança foi objeto de grande difusão na Universidade Livre de Bruxelas, na Bélgica, sendo conhecida por Vasconcelos aquando da permanência nesse país, acompanhando a fundação, em 1906 e 1909, respetivamente da Société Belge de Pédotechnie e Institute Natural Belge de Pédotechnie, com destaque para as figuras de O. Chrisman (impacto da sua obra 'Pédologie: Esquisse d'une Science de l'enfant'), de Decroly e Schuyten (MARTINS, 2019a).

O escolanovista português defende, entre outros pressupostos oriundos da Escola Nova, a autonomia da criança, a adaptação do ensino ao seu desenvolvimento natural, físico-psíquico ou mental, social, estético e moral, dando relevo à cultura (física, intelectual e social) nessas etapas de crescimento, com destaque para o papel escolar dos trabalhos manuais, as excursões escolares, o impacto com a natureza e com a cultura das

comunidades, favoráveis a uma 'cultura integral' das capacidades da criança/adolescência. Paralelamente dá uma atenção específica ao trabalho didático e metodológico do professor/educador ao acompanhar esse desenvolvimento, permitindolhe adequar o ensino às necessidades e interesses da criança, para além de experimentar e observar, diagnosticar, analisar e intervir no seu processo educativo. Faria de Vascon celos vê com bom agrado a intervenção médico-pedagógica na escola, tendo dedicado desde o IOP a analisar os problemas escolares de 'anormalidade escolar' nas escolas (alunos com dificuldades de aprender) classificando-as da seguinte maneira (VASCONCELOS, 1922, p. 20): em 'anormais educáveis' para escolares de reeducação e classes especiais; e 
grandes 'anormais ineducáveis' destinados aos asilos-escolas e colónias agrícolas; e os casos de psiquiatria infantil (patologia mental) e os surdos-mudos.

Pedagogicamente Faria de Vasconcelos constrói o seu pensamento relativamente ao desenvolvimento da criança/adolescente no contexto escolar, na cultura física, intelectual, moral e social. $\mathrm{O}$ meio natural e as atividades físicas 'infraestruturais' ou 'propedêuticas' praticadas na Escola Nova - tipo em Bierges, constitui a base da ideia da "escola às crianças" (VASCONCELOS, 1915, p. 24) em conexão com o sistema do "selfgovernment'. A educação física é por ele considerada o prelúdio da educação intelectual, moral e social, proveniente da conceção, organização e prática pedagógica das Escolas Novas, que de modo eficaz é "a mais generosa preparação para a cultura do espírito, do coração e do carácter da criança” (VASCONCELOS, 1915, p. 67). A própria implantação da escola, situada no campo, expressa um ambientalismo ou naturalismo de que o meio natural da criança constitui a condição favorável ao seu desenvolvimento físico e à sua educação moral. Daí a sua preocupação pedagógica pelos espaços e pelas caraterísticas dos edifícios escolares, os quais deveriam ter ateliers e laboratórios/oficinas, biblioteca escolar e espaços de recreio. Ora o vigor físico e a saúde, em especial a higiene corporal e o regime de vida (nutritiva) eram necessários, não só à cultura do corpo como à cultura intelectual e social e, por isso, analisa (experimenta na escola de Bierges) aspetos como: o sono, a alimentação, o asseio, as lições semanais, a atividade lúdica, os desportos e a ginástica (pedagógica), os trabalhos manuais, os passeios e excursões, etc. (VASCONCELOS, 1915, p. 43-44). As observações e o controlo do ritmo de desenvolvimento físico deveriam ser rigoroso e registado pelo médico e professor e comunicado aos pais/família, de modo a motivar estes para um melhor bem-estar da criança/jovem. Os princípios da continuidade e da solidariedade das funções psíquicas, no âmbito da conexão psicofísica, estão conectados com aquela cultura física do corpo, com a cultura intelectual, moral e social (VASCONCELOS, 1915, p. 67-68).

Em relação à educação intelectual para o nosso escolanovista assentava (VASCONCELOS, 1909): no estudo das relações 'criança-adulto' e 'criança-vida', com a natureza e os trabalhos manuais como os meios envolventes privilegiados; na adaptação do ensino e da educação à evolução natural da criança, segundo as suas necessidades, carências e curiosidades, daí o estudo das línguas vivas; na adaptação do ensino à evolução histórica das ciências na base dos pressupostos da evolução natural da espécie, tendo em conta os princípios da psicologia, da génese das estruturas cognitivas; nos bons métodos de trabalho, como princípios da instrução educativa.

Por conseguinte, para ele o modo de agir do ser humano, no âmbito da psicologia (histórico-cultural) e da Pedagogia, envolve as ações da superação, a cooperação e a emancipação (autonomia) do sujeito, sendo esta a conquista da liberdade de pensamento e ação. Ora Faria de Vasconcelos considera os princípios psicopedagógicos do desenvolvimento humano fundados na pedologia, como fundamentais para a compreensão desse desenvolvimento, seja nas formas de comportamento individual ou coletivo ou de cooperação com outras pessoas, convertendo-se em funções interiores. Assim, o desenvolvimento da criança centraliza-se na constituição do seu sistema psicológico, na articulação com o papel do meio envolvente, com as suas funções mentais e as suas relações e sobre a ideia de sentido e das suas vivências. Por isso, o aspeto afetivo, tal como na teoria vygotiskiana, está na base desse desenvolvimento do psiquismo, em que a subjetividade vai adquirindo uma grande relevância na constituição da própria criança. Deste modo, a configuração do desenvolvimento físico-psíquico e mental é o cerne do problema da educação, não só em detetar as facetas que o influenciam, mas também fornecer subsídios para uma prática educativa organizada com o fim de promover a transição de uma etapa para outro do desenvolvimento da criança. 


\section{Referências}

CLAPARÈDE, Edouard. Psicología del niño (trad. Domingo Barnés). Madrid: Imp. José Blass y C. ${ }^{\text {, }}$ Librería de Francisco Beltrán, 1910

CLAPARÈDE, Edouard. La escuela y la psicología. Buenos Aires: Losada, 1960

FERNANDES, Rogério. A Pedagogia portuguesa contemporânea. Lisboa: ICP/Biblioteca Breve, 2006

FERREIRA, António Aurélio da Costa. Algumas lições de Psicologia e Pedologia. Lisboa: Lumen, 1920.

FERREIRA, António Gomes. A criança e a pedologia no contexto da Primeira República em Portugal. In MOURÃO, Alda; GOMES, Ângela Castro (coord.), A experiência da Primeira República no Brasil e em Portugal. Coimbra: Imprensa da Universidade de Coimbra, p. 299316, 2014. DOI: http://dx.doi.org/10.14195/978-989-26-0862-4_12

FERREIRA, António Gomes. Higiene e controlo médico da infância e da escola. Cadernos CEDES, v.23, n.59, p.9-24, abril, 2003. DOI: https://doi.org/10.1590/S0101-32622003000100002

FERRIÈRE, Adolph Les écoles nouvelles et leur rôle dans la transformation de la pédagogie contemporaine. Bruxelles: Édition L'Institut National de Cinématographie Scientifique, 1955

FIGUEIRA, Manuel Henrique. Um roteiro da Educação Nova em Portugal. Lisboa: Livros Horizonte, 2004.

FONSECA, José Augusto Ferreira da. Estudos médico-sociais sobre proteção a menores anormais e delinquentes. Lisboa: Tipografia Reformatório Central de Lisboa, 1930.

GABLE, Shelly L. \& HAIDT, Jonathan. What (and Why) is Positive Psychology? Review of General Psycholoy, 9(2), p. 103-110, 2005.

GERMÁN, José. Pasado, presente y porvenir de la psicotecnia. Revista Psicología Geral e Aplicada, Vol. X, no 33-36, p. 829-881, 1955.

GOMES, Joaquim Ferreira. A. Faria de Vasconcelos. Revista Portuguesa de Pedagogia (Coimbra), XIV, p. 231-255, 1980.

GUICHOT-REINA, Virginia. Bases pedagógicas de la Escuela Nueva. In BÉRRIO, Julio Ruiz \& CARMEN Sanchidrian (coord.), Historia y Perspectiva actual de la Educación Infantil. Barcelona: Graó, 2010, p. 179-20

LA GAZETA LITERARIA IBÉRICO AMERICANA. Editorial. Año II, no 45 (Madrid), 1 de noviembre, p. 1-2, 1928.

MARQUES, José Henzler Ferreira. Faria de Vasconcelos - Obras Completas, Vol. I. (19001909) Lisboa: F.C.G., 1986. 
MARQUES, José Henzler Ferreira. Faria de Vasconcelos - Obras Completas, Vol. III (19211925). Lisboa: F.C.G., 2006.

MARQUES, José Henzler Ferreira. Faria de Vasconcelos e as suas obras de Psicologia e de Ciências da Educação. Lisboa: Academia de Ciências de Lisboa, 2012.

MARTINS, Ernesto Candeias. Da experiência numa escola nova à educação com crianças 'anormais': Faria de Vasconcelos (1880-1939) no contexto do ensino especial. Acta Scientiarum. Education (Maringá-Brasil), v. 39, n. 2, p. 119-130, abril-junho, 2017. DOI: https://doi.org/10.4025/actascieduc.v39i2.28676

MARTINS, Ernesto Candeias. O ideário científico-pedagógico do escolanovista Faria de Vasconcelos (1880-1939) em prol duma escola nova, inovadora e atual. EccoS Revista Científica, n.48 (jan/mar), p.363-383, 2019a. DOI: https://doi.org/10.5585/eccos.n48.5884

MARTINS, Ernesto Candeias (coord./org.). António Faria de Vasconcelos nos meandros do Movimento da Escola Nova: Pioneiro da Educação do Futuro. Castelo Branco: Edição Câmara Municipal de Castelo Branco /Várzea Rainha Impressores, 2019b (ISBN: 978-989-691-808-8).

PIMENTEL FILHO, Alberto. Pedologia: esboço de uma história natural da criança. 2 vol.s Lisboa: Guimarães \& C. ${ }^{a}, 1929$ (2. ${ }^{a}$ ed. de 1935).

PINELL, Patrice. L'invention de l'échelle métrique de l'intelligence. Actes de la Recherche en Sciences Sociales, 108, juin, p.19-35, 1995. DOI: https://doi.org/10.3406/arss.1995.3145

SANTOS, Alves. O crescimento da criança portuguesa: subsídios para a constituição duma pedologia nacional. Coimbra: Imprensa da Universidade, 1917.

SANTOS, Alves. Educação Nova. As bases. O corpo da criança. Lisboa: Livrarias Aillaud e Bertrand, 1919.

VASCONCELOS, António Faria de. Lições de pedologia e pedagogia experimental. Lisboa: Antiga Casa Bertrand/José Bastos,1909 (2. ${ }^{a}$ ed. Lisboa: Livrarias Aillaud e Bertrand, 1923).

VASCONCELOS, António Faria de. Une école nouvelle en Belgique. Paris/Neuchâtel: Delachaux, \& Niestlée et Librairie Fischabacher, 1915.

VASCONCELOS, António Faria de. Problemas Escolares. 1. a série. Lisboa: Seara Nova, 1921a.

VASCONCELOS, António Faria de. As caraterísticas de educação contemporânea. Seara Nova (Lisboa), 15 de outubro, p. 17-18, 1921 b.

VASCONCELOS, António Faria de. Contribuição para o estudo dos problemas relativos ao nível mental da população infantil de estabelecimentos especiais. Boletim do instituto de Orientação Profissional (Lisboa), 1. a série, no 2-3, p. 19-22, 1922.

VASCONCELOS, António Faria de. Lições de Psicologia Geral. Curso professado na Faculdade de Letras, Vol. 1. Lisboa: Livraria Editora Guimarães, 1925. 
VASCONCELOS, António Faria de. O exame psicológico. Boletim do Instituto de Orientação Profissional (Lisboa), 1. ${ }^{a}$ série, 1, p. 51-65, 1928.

VASCONCELOS, António Faria de. Monographie de L'Institut de Reeducaction Mentale et Pedagogique. Lisboa: Imprensa Lucas \& Ca, 1931.

VASCONCELOS, António Faria de. Uma Escola Nova em Bélgica (Prefácio de A. Ferrière, Pósfácio, Notas e tradução de Carlos Meireles Coelho). Aveiro: Universidade de Aveiro/Theoria, Poiesis e Práxis, Glocal e FCT, 2015 (ISBN: 978-972-789-454-3).

VELOSO, A.J. Barros (coord.). Médicos e Sociedade. Para uma História da Medicina em Portugal no século XX. 2a ed. Lisboa: By The Book, 2017.

VYGOTSKY, Lev Semionovich. Pensamento e linguagem. Lisboa: Antídoto,1979.

WAGNON, Sylvain. Ovide Decroly, un pédagogue de l'Éducation nouvelle 1871-1932. Bruxelles: P.I.E. Peter Lang, 2013. 